REVISTA DE DERECHO UNED, NÚM. 17, 2015

\title{
REGULACIÓN DEL DERECHO DE PROPIEDAD EN VENEZUELA Y LA GOBERNABILIDAD DEL ESTADO A PARTIR DE LA CONSTITUCIÓN NACIONAL DE 1999
}

\author{
REGULATION OF THE COPYRIGHT IN VENEZUELA \\ AND GOVERNANCE STATEMENT FROM THE NATIONAL \\ CONSTITUTION OF 1999 \\ William Pacheco Medina \\ (Abogado Venezuela) \\ JuAN JACOBO NúÑEZ MARTÍNEZ \\ (Universidad Rey Juan Carlos)
}

Resumen: En la República Bolivariana de Venezuela, el Derecho de Propiedad tiene antecedentes constitucionales desde los inicios de la vida republicana en 1811, ha sido consagrado en el artículo 115 de la Constitución Nacional de 1999 (CRBV), y su protección estatal en el artículo 55 constitucional. En consecuencia, el Estado Venezolano sólo de manera excepcional, y por causa de utilidad pública o social, tradicionalmente procedía a expropiar bienes de particulares. Dicho mandato constitucional se ha desarrollado mediante la Ley de Expropiación por Causa de Utilidad Pública o Social, siendo su última versión la de 1958, reformada en 2002.

El marco normativo anteriormente destacado se ha ampliado significativamente a partir de la sanción de la Constitución Nacional de 1999, mediante un conjunto de leyes para normar la afectación de los bienes identificados económicamente como «medios de producción», o de aquellos que en opinión del Gobierno Nacional sean requeridos para la satisfacción de necesidades colectivas. Todo ello bajo 
el impulso político del Ejecutivo Nacional y con la finalidad de consolidar la propuesta del modelo socialista de gestión pública, como se ha plasmado en la generalidad de las exposiciones de motivos de las referidas leyes. Motivo por el cual la afectación a la propiedad privada haya sido calificada por los sectores de oposición política como uno de los aspectos generadores de conflictos y que impacta negativamente en las apreciaciones sobre la Gobernabilidad Democrática del Estado Venezolano. También se estudian aspectos teóricos sobre el vocablo Gobernabilidad.

Abstract: In the Bolivarian Republic of Venezuela, the right of ownership has constitutional history since the beginning of the republic in 1811, has been enshrined in Article 115 of the Constitution of 1999 (Constitution), and state protection in Article 55 constitutional. Accordingly, the Venezuelan state only exceptionally and for reasons of public or social utility, traditionally proceeded to expropriate private property. This constitutional mandate has been developed by the Law of Expropriation for Public or Social, and its latest version 1958, renovated in 2002.

The previously highlighted regulatory framework has expanded significantly since the enactment of the Constitution of 1999, through a series of laws to regulate the allocation of assets economically identified as "means of production", or those in your view National are required for the satisfaction of collective needs. All under the political momentum of the National Executive and with the aim of consolidating the proposal of the socialist model of governance, as has been reflected in most of the preambles to those laws. Why the involvement of private property has been described by political opposition sectors as one of the generators aspects of conflict and a negative impact on the findings on Democratic Governance of the Venezuelan State.

Theoretical aspects of the term Governance, and various studies, research and reports on the democratic governance of states, some with specific views on Venezuela are also studied.

Palabras claves: Propiedad. Gobernabilidad. Democracia. Regulación. Valuación.

Keywords: Property. Governance. Democracy. Regulation. Valuation.

Sumario: 1. Antecedentes. 1.2. Constituciones de 1811 a 1893. 1.3. Constituciones de 1901 a 1953). 1.4. Constitución de 1961. 2. De la Expropiación y su régimen legal. 3. Constitución de 1999. 4. Reflexiones en torno a la propiedad en la Venezuela actual. 


\section{ANTECEDENTES}

Desde la conformación del Primer Estado Liberal en 1811, el derecho a la propiedad ha sido tutelado constitucionalmente por el Estado en Venezuela, equiparándolo con el derecho a la libertad y con el derecho a la igualdad de los ciudadanos. Así se constata en las constituciones proclamadas durante los siglos XIX y XX, en cuyos textos se observa una tendencia garantista que se desarrolla tanto en los Códigos Civiles como en las normas y leyes especiales sobre la materia expropiatoria por causa de utilidad pública o social, especialmente desde 1860 hasta 1947. Destacando que la Ley de Expropiación por Causa de Utilidad Pública o Social de 2002 introduce algunos cambios puntuales, y si ciertamente amplia el campo de acción del Estado, fortalece el aspecto garantista en favor del administrado sujeto de expropiación.

\subsection{Constituciones de 1811 a 1893}

\section{Constitución de 1811}

Inspirada en la declaración Francesa de los Derechos del Hombre (1789) la Constitución de Francia (1791) y en la Constitución de Los Estados Unidos de Norteamérica (1787), se reconoce como la primera Constitución de Venezuela y de Hispanoamérica ${ }^{1}$. En su capítulo VIII, sección segunda, referida a los «Derechos del hombre en Sociedad, artículos 142,152 y153, se proclama:

Artículo 142: "El pacto social asegura a cada individuo el goce y posesión de sus bienes, sin lesión del derecho que los demás tengan de los suyos»

Artículo 152: "Estos derechos son la libertad, la igualdad, la propiedad y la seguridad».

Artículo 155: "La propiedad es el derecho que cada uno tiene de gozar $y$ disponer de los bienes que haya adquirido con su trabajo e industria».

\footnotetext{
${ }^{1}$ Ya en la «Declaración de los Derechos del Pueblo», elaborada por «El Supremo Congreso de Venezuela», antes de la constitución de 1811, se establecían varios artículos que destacaban a la propiedad privada y la obligación del Estado en protegerla y garantizarla. Así, el artículo 2 contempla que: [ ... ] «Consiste esta felicidad en el goce de la libertad, de la seguridad, de la propiedad y de la igualdad de derechos ante la ley»; y el artículo 21 expresa que: «Ninguno puede ser privado de la menor porción de su propiedad sin su consentimiento, sino cuando la necesidad publica lo exige y bajo una justa indemnización». Observándose al respecto un claro antecedente al insalvable requisito de la «Utilidad Pública o Social, presente en la legislación expropiatoria actualmente vigente.
} 
De esta forma, el texto constitucional proclama la propiedad como derecho del hombre en sociedad, a la par del derecho de igualdad y libertad, amparados por el pacto social (el acuerdo de convivencia entre los ciudadanos y el Estado).

En relación con las expropiaciones, el artículo del 165 proclama:

"Todo individuo de la sociedad, teniendo derecho a ser protegido por ella en el goce de su vida, de su libertad y de sus propiedades con arreglo a las leyes están obligado, por consiguiente, a contribuir por su parte para las expensas de esta protección y a prestar sus servicios personales o un equivalente de ellos cuando sea necesario, pero ninguno podrá ser privado de la menor porción de su propiedad ni esta podrá aplicarse a usos públicos sin su previo consentimiento o el de los cuerpos Legislativos representantes del pueblo, y cuando alguna pública necesidad legalmente comprobada exigiere que la propiedad de algún ciudadano se aplique a sus semejantes deberá recibir por ella una justa indemnización».

\section{Constitución de 1819}

Trata sobre la propiedad en sus artículos 1, 12 y 15. En su artículo 1 (Título $1^{\circ}$, de los Derechos y Deberes del Hombre y del Ciudadano. Sección Primera, «Derechos del Hombre en Sociedad) se proclama:

«Son derechos del hombre la libertad, la seguridad, la propiedad y la igualdad». En el artículo 12 expone: "La propiedad es el derecho de gozar y disponer libremente de sus bienes y del fruto de sus talentos, industria o trabajo». Y en artículo 15 señala: "Nadie puede ser privado de su propiedad, cualquiera que sea, sino con su consentimiento, a menos que la necesidad pública o la utilidad general probada legalmente lo exijan. En estos caso la condición de una justa indemnización debe presuponerse».

\section{Constitución de 1821}

Se aprecia en ella la vigencia de las garantías para el propietario, en caso de operar una acción de expropiación excepcionalmente, por «pública necesidad legalmente comprobada». En su artículo 177 se contempla que:

«Ninguno podrá ser privado de la menor porción de su propiedad ni esta será aplicada a usos públicos sin su propio consentimiento o del Cuerpo Legislativo. Cuando alguna pública necesidad legalmente comprobada exigiere que la propiedad de algún ciudadano se aplique a usos semejantes, la condición de una justa compensación debe presuponerse». 


\section{Constitución de 1830}

Se mantienen las garantías y principios consagrados en la constitución anterior, En su artículo 208 se indica: "Ninguno podrá ser privado de la menor porción de su propiedad ni esta será aplicada a usos públicos sin su propio consentimiento o del Congreso. Cuando el interés común legalmente comprobado así lo exija debe presuponerse siempre una justa compensación».

\section{Constitución de 1857}

En su artículo 108 expone que «La propiedad es inviolable y sólo por causa de interés público legalmente comprobado puede el congreso obligar a un venezolano a enajenarla previa justa indemnización». Manteniendo así el régimen de garantías previsto en la constitución anterior, pero calificando de inviolable el derecho a la propiedad, con lo cual regresa a la concepción naturalista, vigente en el Estado de Derecho, y se aparta de la evolución que ya en otros Estados: Alemania, Francia, España e Italia, por citar algunos, apuntan hacia la función social de la propiedad, en el marco de la concepción del Estado Liberal Democrático, y que posteriormente evolucionaría hacia la el "Estado Social y Democrático de Derecho», como se contempla en la Constitución Nacional de 1999, definición esta, y concepción, que indudablemente incidirá en el tratamiento y conceptualización que a la propiedad privada deban otorgarle el Estado y los gobiernos de turno.

\section{Constitución de 1858}

En su artículo 26 se proclama: «Ninguno podrá ser privado de la menor porción de su propiedad ni será aplicada a ningún uso sin su consentimiento o el del Congreso. Cuando el interés común legalmente comprobado así lo exija debe presuponerse siempre una justa compensación». De lo cual se observa una vaguedad en cuanto a precisar el uso público comprobado de la propiedad, y un retroceso en lo referente a no señalarse expresamente la garantía de un previo pronunciamiento judicial firme.

Decretos de los años 1862 y 1863

En el artículo 18 del decreto de 1862 (estando sometido el país bajo el gobierno del General José Antonio Páez y expuesto a un am- 
biente de guerras permanentes) se lee: «Todas las propiedades son inviolables, y cuando el interés público hiciese forzoso el uso de alguna, siempre será con calidad de indemnización». Y en el artículo $1^{\circ}$ del decreto de 1863 (emitido bajo la presidencia de Juan Crisóstomo Falcón) se observa «Se garantiza a los venezolanos: 1. La propiedad: No podrá, pues, su dueño ser despojado de ella, ni privado de su goce por ninguna autoridad, sino en virtud de sentencia judicial». De donde se aprecia la inserción de la garantía expresa de una "sentencia judicial», para concretar el acto expropiatorio. ${ }^{2}$

\section{Constitución de 1864}

Contempla en el título III, sobre Las Garantías de los Venezolanos, en su artículo 14, numeral segundo, lo siguiente:

"Artículo 14. La nación garantiza a los venezolanos:

[...] 2. La propiedad con todos sus derechos, esta sólo estará sujeta a las contribuciones decretadas por la autoridad legislativa, a la decisión judicial y a ser tomada para obras públicas previa indemnización y juicio contradictorio».

De lo que se aprecian dos aspectos. El primero, la calificación expresa de la posibilidad de expropiación sólo para el desarrollo de obras públicas, obviándose en este caso la definición del «interés público», o del «uso público», presente en las constituciones desde 1811. Y el segundo, lo referido a la "previa indemnización», lo cual califica lo oportuno de la misma, pero no lo justo, que son las tendencias actuales. Como se observará en adelante, no fue sino hasta 1947 que se introdujo una variación en lo referente al pago del precio justo por el bien expropiado.

Constituciones de 1874, 1881 y 1891

Mantienen similitud, con las constituciones anteriores y entre ellas, en la redacción del articulado constitucional referido a la propiedad y respecto de la excepción expropiatoria por parte del Estado.

Constitución de 1893

\footnotetext{
${ }^{2}$ Véase al respecto BREWER CARÍAS, Allan R. (1985). "Las Constituciones de Venezuela». Estudio preliminar. Universidad Católica del Táchira. Ediciones del Instituto de Estudios de Administración Local. San Cristóbal. Pág. 401 y siguientes.
} 
Aunque su redacción, en el articulado referido al derecho de propiedad y la materia expropiatoria, es semejante a las Constitución de 1891, incorpora de nuevo la expresión de "utilidad pública» (sustituyendo la de «obras públicas) ampliando así la capacidad expropiatoria del Estado.

\subsection{Constituciones de 1901 a 1953 (siglo xx)}

Constitución de 1901

Se trata sobre la propiedad, y la materia expropiatoria, en el artículo 17 (En el título III, Sección Segunda, sobre los «Derechos de los Venezolanos»). Manteniendo estrecha semejanza con la constitución de 1893. Del referido artículo 17 se lee:

"Artículo 17. La Nación garantiza a los venezolanos la efectividad de los siguientes derechos:

[...] 2. La propiedad, que sólo estará sujeta a las contribuciones decretadas por la Autoridad Legislativa, de conformidad con esta Constitución y a ser tomada para obra de utilidad pública previa indemnización y juicio contradictorio»

Constitución de 1904

Mantiene una redacción semejante a la constitución anterior, en lo referente al derecho de propiedad y la materia expropiatoria, manteniéndose así inalterada la sección correspondiente a «De los derechos de los Venezolanos».

Constituciones de 1909 a de 1922

Mantienen similitud, entre ellas, en la redacción del articulado constitucional referido a la propiedad y respecto de la excepción expropiatoria por parte del Estado. Así, del artículo 23 la Constitución de 1909 se lee:

"Artículo 23. La Nación garantiza a los venezolanos:

[...] 2. La propiedad, con sus atributos, fueros y privilegios: ella sólo estará sujeta a las contribuciones decretadas por la Autoridad Legislativa, a la decisión judicial y a ser tomada para obras de utilidad pública previa indemnización y juicio contradictorio». 
Constituciones de 1925 a de 1931

La Constitución nacional de 1925 introduce la novedad de obligar a los propietarios a la conservación e higiene de sus bienes, además de referirse a la conservación de los bosques, aguas y otros recursos de interés a la comunidad. Su redacción en lo referente a la propiedad y la materia expropiatoria se mantiene en las constituciones de 1928 y 1931. Así, en el artículo 32 le lee:

"Artículo 32. La nación garantiza a los venezolanos:

[...] 2. La propiedad, que sólo estará sujeta a las contribuciones legales y a ser tomada para obras de utilidad pública, previo juicio contradictorio e indemnización determine la ley. También estarán obligados los propietarios a observar disposiciones sobre higiene pública, conservación de bosques y aguas, y otras semejantes que establezcan las leyes en beneficio de la comunidad».

\section{Constitución de 1936}

Oportuno es referirnos al contexto histórico en que se dicta la constitución de 1936, durante el Gobierno del General Eleazar López Contreras y posterior a la muerte del General Juan Vicente Gómez (quien gobernó a Venezuela de manera dictatorial durante 27 años), debido a que se dan los primeros pasos institucionales para avanzar hacia la vida en democracia y el desarrollo económico, debido a la ampliación de los derechos civiles y políticos, la legalización de los partidos políticos y a la presencia del petróleo en la economía nacional. Lo cual generó un clima de cambios en el acontecer político, económico y social en el país.

En relación con la propiedad, se mantienen los derechos y garantías presentes en la constitución de 1931, pero incorporándose un marco de restricciones en cuanto a la potestad de los propietarios para transferir determinados activos, en virtud de sus particulares características, o ubicación estratégica para el interés nacional. También se especificó y amplió lo referente a las confiscaciones de bienes en propiedad de funcionarios públicos (Expresidentes, Exministros, Exgobernadores, Expresidentes y Exsecretarios Generales de las Asambleas Legislativas de los Estados), cuando estos hubiesen incurrido (a juicio del Congreso Nacional) en delitos contra la Cosa Pública y contra la propiedad. De lo cual se observa la clara intención de corregir algunos actos dolosos perpetrados el régimen dictatorial, pero dicha medida se extendió hasta los bienes adquiridos por heren- 
cia, y abarcando las actuaciones de los funcionarios hasta por dos períodos presidenciales.

Del artículo 32 se puede leer:

"Artículo 32. La nación garantiza a los venezolanos:

[...] 2. La propiedad, que es inviolable, estando sujeta únicamente a las contribuciones legales. Sólo por causa de utilidad pública o social, mediante juicio contradictorio e indemnización previa, podrá ser declarada la expropiación de ella, de conformidad con la ley. Los propietarios estarán obligados a observar las disposiciones sobre Higiene Pública, conservación de bosques y aguas, y otras semejantes que establezcan las leyes en beneficio de la comunidad. [...]

Más adelante, en el referido artículo, se trata lo referente a las «restricciones y prohibiciones especiales para la adquisición y transferencia de determinadas clases de propiedad», y lo correspondiente a las confiscaciones de los bienes bajo la propiedad de funcionarios públicos.

\section{Constitución de 1945}

En relación con la propiedad, y la materia expropiatoria, en el artículo 32 constitucional se lee:

"Artículo 32. La nación garantiza a los venezolanos:

2. La propiedad, que es inviolable está sujeta a las contribuciones, y a las restricciones y obligaciones que establezca la ley por razones de interés público o social. Puede la ley, inclusive establecer prohibiciones especiales para la adquisición, transferencia, uso y disfrute de determinadas clases de propiedad, sea por su condición, lo por su situación en el territorio nacional.

De conformidad con la ley, sólo por causa de utilidad pública o social, mediante indemnización previa y juicio contradictorio, podrá ser declarada la expropiación de la propiedad o de algún derecho.

No se decretará ni se llevarán a cabo confiscaciones de bienes sino contra los extranjeros y únicamente en caso de conflicto internacional con su país».

De lo que se observa: 1) en principio, un retroceso legislativo en la materia, al no precisarse la potestad expropiatoria del Estado, y sólo someter la propiedad a «las contribuciones, y las restricciones y obligaciones que establezca la ley por razones de interés público o social»; y 2) una evidente motivación política de pacificación interna, revestida de un carácter nacionalista, al reservar las acciones de con- 
fiscación sólo a los ciudadanos extranjeros, con nacionalidad en países que mantengan conflictos con Venezuela; abandonando el planteamiento que al respecto contiene el artículo 32 de la Constitución de 1936.

\section{Constitución de 1947}

Debemos observar, que desde la Constitución de 1864 y hasta la sanción de la Constitución de 1947 la Técnica Legislativa adoptada en materia del régimen de propiedad y expropiaciones se mantiene de forma coincidente en sus aspectos generales y sólo con particulares variaciones, como ya lo hemos destacado. Pero es a partir de 1947 cuando por primera vez el derecho de propiedad no se inserta en el capítulo sobre «Los Derechos de los venezolanos», presentándose en el capítulo VII »De la economía nacional». De allí que resulte oportuno el comentario que al respecto la Dra. Samantha Sánchez Miralles (2011) introduce en su comentado trabajo, cuando nos expone que esta particularidad es: [ ... ] «lo que ha dado origen a la interpretación de que la propiedad pasó a tener un rasgo distinto dentro de los derechos constitucionales, menor y ya no ser un robusto derecho fundamental». ${ }^{3}$

De la referida normativa, en su articulado sobre la propiedad, a rasgos generales, destacamos lo siguiente: En su artículo 65 se garantiza el derecho de propiedad y destaca la función social de la misma. El artículo 67 trata sobre la «expropiación de cualquier clase de bienes», pero introduce un tratamiento especial para las tierras destinadas a realización de la reforma agraria (estandarte de lucha expuesto por, el para entonces Presidente de la Junta Revolucionaria de Gobierno, Rómulo Betancourt), precisando que en ningún caso se decretarán las confiscaciones de bienes, y remitiendo para las excepciones al artículo 21 de la Constitución (que al respecto, mantiene la redacción del artículo 32 de la constitución anterior). El artículo 68 establece las condiciones para la propiedad de tierras y bosques en función de la producción socialmente útil

También en el año 1947 se sancionó la primera ley con visión universal sobre el desarrollo jurídico en la materia expropiatoria: Ley de Expropiación de por Causa de Utilidad Pública o Social (con antece-

${ }^{3}$ SÁNCHEZ MIRALLES, Samanta (2011). «Expropiación de Marca en Venezuela (Particular enfoque desde el punto de vista del análisis económico del derecho)». Edit. FUNEBA. Caracas. Obra citada. P. 47. 
dentes legislativos desde 1860), ${ }^{4}$ con evidente motivación hacia la solución de los problemas sociopolíticos que impulsaron la Ley de Reforma Agraria.

\section{Constitución de 1953}

Esta Constitución se sanciona bajo el gobierno de Marcos Pérez Jiménez, quien llegó al poder en 1952, estando para entonces en vigencia la Constitución Nacional de 1945, debido a que la coalición de gobierno que derrocó al presidente Rómulo Gallegos en 1948 derogó la novel constitución de 1947 y puso de nuevo en vigencia la constitución de 1945. De lo cual se aprecia todo el juego de intereses políticos presente para entonces, y la preferencia del gobernante de turno por una Carta Magna que propiciara la concentración del poder y la intervención del Estado en las decisiones económicas (impactadas por el auge de la explotación petrolera y minera). Y aunque el derecho de propiedad recobra su estatus dentro de las garantías para «los habitantes de Venezuela», no se aprecian cambios fundamentales en la materia referida a la propiedad y las expropiaciones, con relación a la constitución anterior.

En el artículo 35 constitucional se define el derecho a la propiedad, se establece la expropiación y las prohibiciones especiales para la propiedad de bienes con características estratégicas para la nación. Apreciamos al respecto:

"Artículo 35. Se garantiza a los habitantes de Venezuela:

[...] 9. El derecho de propiedad. En virtud de su función social la propiedad estará sometida a las contribuciones, restricciones y obligaciones que establezca la ley de conformidad con la cual también podrá ser declarada la expropiación de cualquier clase de bienes mediante sentencia firme y pago del precio.

La ley podrá establecer prohibiciones especiales para la adquisición, transferencia, uso y disfrute de determinadas clases de propiedad, por su naturaleza, condición o situación en el territorio nacional.

Las tierras adquiridas y destinadas a la explotación de concesiones mineras, de hidrocarburos y demás minerales combustibles pasarán en plena propiedad a la Nación, sin indemnización alguna, al extinguirse por cualquier causa la concesión respectiva.»

${ }^{4}$ Ley de Expropiación por Causa de Utilidad Pública o Social. Gaceta Oficial de los Estados Unidos de Venezuela. N 22.458, de 6 de noviembre de 1947.

(C) UNED. Revista de Derecho UNED, núm. 17, 2015 


\subsection{Constitución de 1961}

Es el antecedente constitucional de la vigente constitución de 1999, que en materia de propiedad y su expropiación por parte del Estado, sólo incorporó aspectos puntuales, manteniéndose vigentes los fundamentos y garantías, lo que precisaremos en adelante.

Su importancia histórica y aporte para la vida institucional y democrática del país se aprecia de lo expuesto por Rodríguez Barrera, Alberto (2013), quien resume ${ }^{5}$ :

«La Constitución de 1961, en 150 años de vida independiente, sería el número 26 de las constituciones promulgadas. La República vivió casi todo el siglo 19 y buena parte del siglo 20, entre asonadas y guerras civiles, con sus secuelas de autocracias y despotismos, en un vórtice de violencias desatadas y de mandonerías imperiosas que impidieron estabilizar las normas jurídicas que dieran fisonomía a un Estado democrático, y así se frustró por muchos años la intención de los padres de la patria al redactar la Constitución de 1811 y la del Libertador cuando elaboró las bases constitucionales del Congreso de Angostura. Se falsearía la verdad histórica de imputarse como responsabilidad exclusiva de los imperiosos régulos de montonera o de cuartel elevados por asalto a la Presidencia de la República el desconocimiento de la norma constitucional y la elaboración de cartas fundamentales hechas a la medida de su voluntad de dominio incontrastado» [...].

Así, para resaltar la importancia de la Constitución de 1961, y en evidente crítica a los acontecimientos y liderazgos que impulsaron la vigente Constitución de 1999, continúa exponiendo:

[...] «La Constitución de 1961 ha sido la más importante que ha tenido en toda su historia la República de Venezuela. Ha sido la de mayor estabilidad. Tuvo vigencia desde enero de 1961 hasta diciembre de 1999 (la de 1830 permaneció 27 años, la de 1864 se prolongó por 10 años). No fue una Constitución sectaria, monocolor, redactada por un grupo de acríticos de una secta regresiva. Por el contrario, fue confeccionada con espíritu nacional, interpretando no el capricho de un caudillo, sino la voluntad de los representantes de la elección democráticamente más amplia que había tenido el país».

Regresando al tema que nos ocupa, debemos compartir lo señalado por la Dra. Samantha Sánchez Miralles $(2011)^{6}$, anteriormente citada, cuando destaca que la base constitucional que normó la materia expropiatoria durante 38 años en Venezuela se resume en los artículos 99, 100, 101,102 y 103 de la Carta Magna para entonces, insertos en el capítulo de los Derechos Económicos, siguiendo la orientación iniciada

${ }^{5}$ RODRÍGUEZ BARRERA, Alberto (2013). Artículo: «La Constitución de 1961, la más importante de nuestra historia». Disponible en: www. noticierodigital.com

${ }^{6}$ SÁNCHEZ MIRALLES, Samanta (2011). Obra citada. Págs. 50-51 
en 1947. La autora cita a Ignacio de León, cuando comenta que: «los derechos fundamentales a la libertad económica y la propiedad fueron suspendidos al día siguiente de haber sido promulgada la Constitución de 1961, y se mantuvo suspendida por 30 años por razones excepcionales, sin que nadie explicara esta suspensión adecuadamente» ${ }^{7}$. Del articulado referido, en el Capítulo V. Derechos Económicos, se puede leer:

"Artículo 99. Se garantiza el derecho de propiedad. En virtud de su función social la propiedad estará sometida a las contribuciones, restricciones y obligaciones que establezca la ley con fines de utilidad pública o de interés general».

Artículo 100. Los derechos sobre obras científicas, literarias y artísticas, invenciones, denominaciones, marcas y lemas gozarán de protección por el tiempo y en las condiciones que la ley señale.

Artículo 101. Sólo por causa de utilidad pública o de interés social, mediante sentencia firme y pago de justa indemnización, podrá ser declarada la expropiación de cualquier clase de bienes. En la expropiación de inmuebles, con fines de reforma agraria o de ensanche y mejoramiento de poblaciones, y en los casos que por graves razones de interés nacional determine la ley, podrá establecerse el diferimiento del pago por tiempo determinado o su cancelación parcial mediante la emisión de bonos de aceptación obligatoria, con garantía suficiente.

Artículo 102. No se decretarán ni ejecutarán confiscaciones sino en los casos permitidos por el artículo 250. Quedan a salvo, respecto de extranjeros, las medidas aceptadas por el derecho internacional.

Artículo 103. Las tierras adquiridas con destino a la exploración o explotación de concesiones mineras, comprendidas las de hidrocarburos y demás minerales combustibles, pasarán en plena propiedad a la $\mathrm{Na}$ ción, sin indemnización alguna, al extinguirse por cualquier causa la concesión respectiva.»

El artículo 250 referido en el artículo 102, en relación con el tema que nos ocupa, trata sobre la incautación de bienes a los funcionarios públicos que se hubiesen enriquecido en el ejercicio de sus funciones. De él se pude leer:

«Título XI. De la Inviolabilidad de la Constitución. Artículo $250^{\circ}$ Esta Constitución no perderá su vigencia si dejare de observarse por acto de fuerza o fuere derogada por cualquier otro medio distinto del que ella misma dispone. [...]

[...] En tal eventualidad, todo ciudadano, investido o no de autoridad, tendrá el deber de colaborar en el restablecimiento de su efectiva

${ }^{7}$ DE LEÓN, IGNACIO (2007). A cinco años de la Constitución económica de Venezuela, un balance de gestión. Citado por Sánchez Miralles, Samanta (2011). Obra citada. Pág. 51. 
vigencia. Serán juzgados según esta misma Constitución y las leyes expedidas en conformidad con ella, los que aparecieren responsables de los hechos señalados en la primera parte del inciso anterior y asimismo los principales funcionarios de los gobiernos que se organicen subsecuentemente, si no han contribuido a restablecer el imperio de esta Constitución. El Congreso podrá decretar, mediante acuerdo aprobado por la mayoría absoluta de sus miembros, la incautación de todo o parte de los bienes de esas mismas personas y de quienes se hayan enriquecido ilícitamente al amparo de la usurpación, para resarcir a la República de los perjuicios que se le hayan causado».

Se verificaban entonces las siguientes características de la propiedad:

a. Es una institución de Derecho Público, debido a que el ente expropiante actúa en ejercicio de sus atributos de imperio, representando el interés general. Por tanto la relación jurídica que se crea entre el Estado y los administrados se rige por el Derecho Público.

b. Se debe realizar con fines de utilidad pública o social, de acuerdo con el Artículo 101 de la Constitución Nacional. En tal sentido se debe tener presente que:

- La calificación de la utilidad pública o social del fin perseguido la debían determinar los órganos legislativos y excepcionalmente los ejecutivos. Pero en la práctica resultaba innecesaria tal declaratoria, en atención con lo estipulado en la Ley de Expropiación por Causa de Utilidad Pública o Social vigente.

- Para el momento, ya otras leyes también trataban sobre la materia, como es el caso de la Ley de reforma Agraria y la Ley de Minas, entre otras.

c. Es una decisión unilateral de la Administración (además de tener carácter coactivo).

d. El expropiado debe recibir una justa indemnización.

- Significa que la suma a pagar en la expropiación debe cubrir el daño que se causa al expropiado, pero de tal forma que éste no se enriquezca ni empobrezca..

- Se concreta como principio general el considerar que La indemnización deba ser previa a la traslación de la propiedad al órgano público. Sin el cumplimiento de este requisito la propiedad no debía pasar al ente expropiante.. 
- Se precisan excepciones a la justa indemnización, como por ejemplo las contempladas en la ley de Reforma Agraria, y la acordada como medidas para el mejoramiento de la población, entre otros casos determinados Ley.

De lo cual se puede concluir que La Constitución Nacional de 1961 garantizaba la inviolabilidad del derecho de propiedad, pero a la vez permitía la expropiación, ya que el Estado para la realización de los fines de su gestión de interés público, tiene necesidad de ciertos bienes pertenecientes a los particulares, y ante el conflicto de ambos intereses lógicamente tiene que ceder el interés privado frente al de la colectividad. Lo cual se ubica en la tendencia moderna en la materia, vigente y potenciada en nuestros días.

\section{DE LA EXPROPIACIÓN Y SU RÉGIMEN LEGAL}

\section{A) De la Ley de Expropiación de 1947}

La ley de Expropiación vigente en 1961, como ya se indicó, es la ley sancionada el 6 de noviembre de 1947. Esta normativa especial inicia la modernidad en la materia, y tuvo su origen en la ley del 13 de julio de 1860, señalándose desde entonces los casos en los cuales podía considerarse la utilidad pública de alguna propiedad. Y como lo destaca Casanova González, ${ }^{8}$ Antonio (2009) al citar a Tomas Polanco Alcántara, dicha ley fue objeto de varias reformas durante los años 1891, 1892, 1912, 1918,1923, 1945, y 1946.

Evolucionando en paralelo ciertas disposiciones en los códigos civiles, hasta llegar a la versión inserta en el Código Civil de 1942, en su Título II (De la Propiedad). Capítulo I (Disposiciones generales), artículos 545 al 549, cuya última reforma legislativa es la contenida en el Código Civil de 1982, actualmente vigente. Del referido código, en sus artículos 545 se lee: "Artículo 545. La propiedad es el derecho de usar, gozar y disponer de una cosa de manera exclusiva, con las restricciones y obligaciones establecidas por la ley. Artículo que define a la propiedad, y se desarrolla en los artículos 547 (sobre la cesión obligatoria de la propiedad); 549 (sobre la propiedad del suelo); 582 (sobre los derechos del usufructo, uso y habitación); 644 (sobre las limitaciones a la propiedad predial); 709 (sobre la servidumbre); 726 (sobre el ejercicio de los dere-

${ }^{8}$ CASANOVA GONZÁLEZ, Antonio Antonio. HERRERA ORELLANA, LUIS ALFONZO Y ANZOLA SPADARO, Karina (2009). "¿Expropiaciones o Vías de Hecho? (La degradación continuada del derecho fundamental de propiedad en la Venezuela actual)». UCAB. FUNEDA. Caracas. Pág. 63. 
chos provenientes de limitaciones y servidumbres) y 796, referido a la adquisición y traspaso de la propiedad. En cuanto a la expropiación, y en desarrollo del artículo 101 constitucional, del artículo 547 se observa:

"Artículo 547. Nadie puede ser obligado a ceder su propiedad, ni a permitir que otros hagan uso de ella, sino por causa de utilidad pública o social, mediante juicio contradictorio e indemnización previa. Las reglas relativas a la expropiación por causa de utilidad pública o social se determinará por leyes especiales».

En relación con lo anterior (base constitucional y normativa civil), observamos del artículo 35 de la Ley de Expropiación por Causa de Utilidad Pública o Social, lo siguiente:

a) En cuanto al justiprecio, dicho artículo contempla que para toda finca, o derecho, que se trate de expropiar total o parcialmente, se especificará su clase, calidad, situación, dimensiones aproximadas, su probable producción y todas las otras circunstancias que influyen en las operaciones y cálculos que se hayan hecho para fijar su justo valor, las cuales también se especificarán. Entre los elementos del avalúo, establecía que se tomarán en cuenta el valor fiscal del inmueble declarado o aceptado por el propietario: el valor establecido en los actos de transmisión realizados por lo menos 6 meses antes del Decreto de Expropiación y los precios medios a que se hayan vendido en los últimos doce meses inmuebles similares. En ningún caso podía ser tomado en cuenta el mayor valor de los inmuebles por razón de su proximidad a los otros en proyecto.

b) Cuando el justiprecio versara sobre parte de una finca o derecho, debía formar Capítulo separado la cantidad en que se estime el perjuicio sufrido por el propietario con la expropiación parcial, teniendo en cuenta el beneficio inmediato y permanente que la construcción de la obra que da lugar a la expropiación reporte al costo de la finca o derecho de que se trate. Si la estimación del beneficio excediese a la del perjuicio, el exceso debía imputarse al valor de la parte expropiada. En todo caso si el exceso fuese mayor de un cuarto de la indemnización debida al propietario, podía éste optar por la expropiación total declarando la aceptación del justiprecio precedentemente exceptuado. De su parágrafo único se puede leer:

«De la misma manera se hará y presentará el justiprecio de las mejoras y perjuicios del poseedor. La regulación que establece esta norma para la actividad de los expertos vale tanto para la fase del procedimiento administrativo como del procedimiento judicial. La infracción de esta norma por los expertos acarreará la invalidez de sus actuaciones. Los peritos no pueden realizar su dictamen conforme a su leal saber y entender sino que deben cumplir las normas que establece la ley.» 
$\mathrm{Al}$ respecto ha resultado fundamental el aporte científico que en materia valuatoria (metodología, procedimientos y cálculos) han aportado los colegios de Profesionales y las Asociaciones de Tasadores, entre las que ha destacado, en un principio, la Sociedad de Ingeniería de Tasación (SOITAVE), antes ASOTAVE adscrita al colegio de Ingenieros y relacionada con asociaciones de tasación internacionales. Y ya en tiempos más recientes, LA SOCIEDAD DE Economistas Tasadores de Venezuela (SOVECTA).

c) En cuanto a los bienes objeto de expropiación, la referida ley precisa que esta podía versar sobre todos los bienes muebles, bienes inmuebles, bienes corporales, bienes incorporales, derechos reales, derechos personales, y bienes de la Nación, de los Estados y de los Municipios.

d) En cuanto a los requisitos para que proceda la expropiación, se tipificaron cuatro, criterio que como observaremos en adelante se ha mantenido para esta ley:

1. La declaratoria de utilidad pública, o interés social, por parte de:

- Las autoridades legislativas

- Los órganos colegiados del Estado

- La declaratoria general de utilidad pública, por el Ejecutivo Nacional.

2. El Decreto de Expropiación.

- Consiste en la declaración de que la ejecución de una obra afecta determina zona y por lo tanto se requiere la adquisición forzosa de la totalidad o parte de uno o varios inmuebles determinados.

- Compete a las autoridades administrativas:

- Presidente de la República - orden Nacional

- Gobernador - Orden estatal.

- Consejos Municipales - orden municipal.

3. El Justiprecio.

- La Constitución de 1947 lo calificaba como: «Pago del precio».

- La Constitución de 1961 se refirió a él como: «Una justa indemnización», aunque para el justiprecio, en el artículo 36 de la ley de expropiación, fueran estimados otros daños, y 
4. El pago de la justa indemnización, se estableció como condición indispensable para que se llevara a efecto la transferencia de la propiedad del expropiado al expropiante.

En relación a los elementos a considerar para el avalúo, resulta obvio apreciar que la ley no pudo prever todos los factores que pudiesen ser tomados en cuenta para realizar una operación tan compleja, y especializada, como lo es la tasación de activos tangibles inmuebles, maquinas, equipos, etc.). Es por consiguiente que la jurisprudencia fue consolidando la tendencia de que la ley da a los peritos amplia libertad para tomar en cuenta ciertos elementos no determinados en ella, lo que fue permitiendo la amplitud para que los tasadores pudiesen identificar y aplicar las metodologías y principios necesarios, y específicos según el bien tasado, para la elaboración de sus informes de avalúo. No obstante, en el caso de los bienes inmuebles, la ley señalaba al mismo tiempo los tres elementos que obligatoriamente se debía apreciar, siempre que fuese posible determinarlos o conocerlos. Estos son: 1) El valor fiscal del inmueble declarado, o aceptado por el propietario; 2) El valor establecido en actos de transmisión realizados por lo menos seis meses antes del decreto de expropiación, y 3) Los precios medios a que se hubiesen vendido inmuebles similares, en los últimos doce meses. Criterios que en la práctica, y según los casos, se adaptaron para otros activos fijos. ${ }^{9}$ En relación con la valoración de inmuebles, y a los fines de determinar su valor comercial, las operaciones a que se refiere la ley, debían ser las que aparezcan en los registros inmobiliarios (y no precios de ofertas en el mercado: prensa, etc. $)^{10}$.

${ }_{9}^{9}$ Debemos referir al respecto el contenido del artículo 100 de la Constitución Nacional de 1961, que trata sobre activos intangible, del cual se lee: «Los derechos sobre obras científicas, literarias, y artísticas, invenciones, denominaciones, marcas y lemas gozarán de protección por el tiempo y en las condiciones que la ley señale». Observando que la metodología valuatoria para esta clase de activos se fundamenta en criterios del valor en el mercado y financieros, totalmente diferentes a la metodología generalizada universalmente para la tasación de bienes inmueble. Como señalaremos en adelante, ya en vigencia de la constitución nacional de 1999, ese será uno de los criterios discrepantes al momento de la valoración de plantas industriales, marcas y patentes, por la negativa de los representantes del Gobierno en admitir justiprecio sobre este tipo de activos, generando en consecuencia reclamos por la vía jurisdiccional (además de las demandas por considerar incumplida la normativa constitucional y legislación expropiatoria vigente para entonces).

${ }^{10}$ Los documentos autenticados tienen fecha cierta y surten todos sus efectos entre las partes, pero, es sólo la formalidad del registro lo que los hace oponibles ante terceros y como prueba en actos administrativos o por la vía en actos judicial (Artículo 35 y artículo 21 de la Ley de Expropiación por causa de Utilidad Pública o Social). Criterio que se mantiene hasta el presente, pero con la problemática que se presenta al tratar de obtenerse dicha información, por el atraso y mala administración en la generalidad de las oficinas de registro inmobiliario del país. 
Resulta oportuno destacar que la gestión del experto tiene el carácter de función pública, debido a que su designación tiene un origen dentro de un procedimiento tutelado por un Tribunal de la Nación, y su actividad está sujeta a las normas que prevé la ley. Pudiendo además ser impugnado por las partes (ente gubernamental expropiante, o expropiado). Observaremos en adelante ligeras variantes, al revisar la legislación sobre expropiaciones vigente bajo la Constitución de 1999.

\section{B) De la Ley de Reforma Agraria (algunas generalidades)}

Fue promulgada el 5 de Marzo de 1960, para regular las expropiaciones en materia agraria. Teniendo como finalidad la distribución equitativa de la propiedad de la tierra. Siendo relevante precisar que se consideraban inexpropiable para los fines de reforma agraria: a) Los predios rústicos que cumplen su función social conforme al artículo 19 de la Ley de la materia; b) Los terrenos o fundos cuya extensión no excediera de 150 hectáreas, tierras consideradas de primera clase o sus equivalentes en tierras de otras calidades, de conformidad con el Reglamento de la ley, y c) Las tierras de propiedad privada inexpropiables podían llegar a serlo cuando fuere necesario establecer una organización agraria, y cuando el bien objeto de expropiación significara un obstáculo para tal fin.

A manera de resumen, el procedimiento expropiatorio contemplaba:

a) Al Instituto Agrario Nacional (IAN), le correspondía gestionar el arreglo amistoso; b) No logrado el arreglo amistoso debía solicitar la expropiación sin necesidad de previa declaratoria de utilidad pública, por ser de utilidad pública, conforme a la Ley de Reforma Agraria las expropiaciones de tierras o fundos a los fines en ella previstos; c) El dictamen de los peritos en materia agraria debía tomar en cuenta, además de las normas de la Ley de Reforma Agraria las normas generales de la Ley de Expropiación por Causa de Utilidad Pública o Social Artículo 25 y la Ley de Reforma Agraria, Artículo 35; d) Cuando no fuese posible dar cumplimiento a todos los requisitos la de Expropiación por carencia de elementos de juicio, los peritos lo deben hacer constar expresamente en el texto del informe.

La diferencia fundamental de los procedimientos entre ambas leyes se resume sólo en formalidades. Así, en la Ley de expropiación, el avenimiento se realizaba después de la sentencia firme declarativa de la expropiación, y en la Ley de Reforma Agraria: Las partes concurrían en la audiencia siguiente al acto de contestación, con el propósito de lograr un avenimiento, y en caso de no lograrse se nombrarían los peritos en la audiencia siguiente. 


\section{CONSTITUCIÓN DE 1999}

Con ella se viene desarrollando en Venezuela una política de expropiaciones sin precedentes en el país, y que si bien, en principio, ha favorecido a amplios sectores populares de la población, no es menos cierto que también se hayan afectado intereses particulares, y hasta colectivos según su interpretación, garantizados por la vigente Constitución y por las anteriores, en evolución progresiva del fundamento constitucional del derecho de propiedad desde la primera constitución de $1811^{11}$.

El marco normativo anteriormente señalado se ha ampliado significativamente a partir de la Constitución Nacional de 1999, para normar la afectación de los bienes identificados económicamente como «medios de producción», o de aquellos que en opinión del Gobierno Nacional sean requeridos para la satisfacción de necesidades colectivas, algunas veces de índole coyuntural. Todo ello bajo el impulso político del Ejecutivo Nacional y con la finalidad de consolidar la propuesta del modelo socialista de gestión pública, como se ha plasmado en la generalidad de las exposiciones de motivos de las referidas leyes.

Dentro de la normativa con afectación al derecho de propiedad en Venezuela, las expropiaciones en Venezuela se han calificado con una gran importancia para su estudio y atención en foros de opinión profesional y política, debido al particular tratamiento con el cual han sido caracterizadas por los equipos de Gobierno a partir de la sanción de la Constitución Nacional de 1999, al ampliarse la conceptualización tradicional de la utilidad pública o social, antes referida generalmente al requerimiento de tierras e inmuebles varios para incorporarlos al uso colectivo, o por ser necesarios para la construcción de obras públicas.

El Gobierno Nacional ha avanzado con la política de expropiaciones, en un principio, alegando el derecho a la soberanía alimentaria,

${ }^{11}$ Para una revisión del marco histórico en el cual se convocó y desarrolló el proceso constituyente que dio origen a la Constitución de 1999, resulta un ejercicio pedagógico la revisión del planteamiento del Dr. Allan Brewer Carías, en la primera parte de su texto «La Constitución de 1999». Allí se expone con detalles las discrepancias políticas, y soluciones jurídicas, que se originaron en torno a la convocatoria de la asamblea constituyente y sus facultades administrativas, toda vez que la Constitución de 1961 no contemplaba la convocatoria de la referida instancia política por esta vía, razón por la cual se desarrolló todo un debate en torno a la supremacía constitucional vs la soberanía popular, inclinándose hacia la segunda la decisión de la Corte Suprema de Justicia, para entonces el máximo tribunal nacional. 
para garantizar los procesos productivos y de distribución de alimentos para la población, pero posteriormente la política de expropiaciones se ha diversificado basada en motivaciones coyunturales, según haya sido la necesidad del Gobierno de ampliar y asegurar el control de los medios de producción y prestaciones de servicios, llegándose al extremo de desconocerse la propiedad privada en algunas normativas con articulado referido a limitaciones sobre la propiedad, cuando el propietario de determinado activo haya sido procesado por la presunta comisión de algunos de los delitos tipificados en las mismas. De las cuales citamos como ejemplo a la Ley de Precios Justos (del 23-01-2014), que dentro de su procedimiento administrativo contempla la ocupación (temporal y previa), la posesión y el uso de los bienes, y la posterior confiscación, más no la expropiación de los activos. Con lo cual se estarían desconociendo derechos patrimoniales preexistentes (y no necesariamente originados por las presuntas acciones delictivas sancionadas) y hasta derechos de sucesión, todos ellos amparados por la Constitución Nacional venezolana.

Entre las causas de malestar más comunes tenemos el pago no oportuno del correspondiente y obligatorio justiprecio, y el desconocimiento de los efectos del mercado y la inflación en momento de proceder con la valoración de los activos objeto de expropiación. Cuestionándose además, que alegando el Estado la falta oportuna de recursos para pagar los justiprecios correspondientes a los legítimos propietarios (lo cual deprecia el valor presente de los referidos activos), sin embargo se haya seguido ejecutando las expropiaciones a diferentes propiedades privadas en todo el territorio nacional, inobservándose la aplicación estricta de lo establecido en la nuestra Carta Magna, y la legislación vigente sobre la materia, según sea el caso. Razón por la cual sectores de oposición y autores de trabajos varios señalen la afectación a la propiedad privada como un aspecto generador de conflictos socio-políticos, que impacta negativamente en las apreciaciones sobre la Gobernabilidad Democrática del Estado Venezolano. En cuanto a la causal de utilidad pública o interés social, en el caso de las expropiaciones de viviendas y apartamentos, de la bibliografía revisada y opiniones consultadas, se puede apreciar que en algunas partes del territorio nacional se han elaborado decretos de expropiación de edificios alquilados o desocupados para una posterior reventa o adjudicación a un tercero, no cumpliéndose así el objetivo final de la expropiación, el cual es que el bien quede en el patrimonio del Estado y que las edificaciones puedan ser utilizadas por cualquier ciudadano y no por uno determinado. No está contemplado en la norma expropiatoria la circunstancia de expropiar a un particular para beneficiar a otro. Al estudiarse algunas medi- 
das judiciales sobre las prohibiciones de ventas de inmuebles, y constatarse el funcionamiento administrativo en las instancias públicas, se aprecia que los entes gubernamentales se han dedicado a emitir un sin número de oficios a los Registros Inmobiliarios y a Tribunales Ejecutores, prohibiendo cualquier tipo de negociación sobre determinados bienes, por lo que los propietarios de los mismos han perdido, por vía de hecho, la posesión y disposición de sus inmuebles, configurándose una medida expropiatoria indirecta.

Es así, como de lo planteado por diferentes autores, se puedan tipificar otras modalidades de expropiaciones en Venezuela y avanzar en su estudio. Antonio Casanova González (2009) ${ }^{12}$ en su texto «Expropiaciones o Vías de Hecho», expone que además de las expropiaciones alegándose el derecho a la soberanía alimentaria, el Gobierno Nacional ha realizado expropiaciones de bienes inmuebles y muebles por razones varias como: 1) la expropiación forzosa de la propiedad privada por acciones públicas, 2) expropiación de tierras por desconocimiento de la condición de propietarios por parte de la Administración; 3) expropiaciones forzosas de empresas o industrias de propiedad privada y 4) casos de «expropiaciones indirectas» o de medidas administrativas que surten efectos equivalentes a la apropiación forzosa de la propiedad privada.

Con basamento en la normativa vigente, respecto a la conceptualización de libre iniciativa y la propiedad privada existen en este país. Para tal fin se observó, en principio, lo contemplado en los artículos 112 y 115 de la Constitución de la República Bolivariana de Venezuela (CRBV), cuyo texto oficial fue publicado en la Gaceta Oficial Extraordinaria $\mathrm{N}^{\circ} 5453$ del 24 de marzo de 2000. El primero establece que «Todas las personas pueden dedicarse libremente a la actividad económica de su preferencia, sin más limitaciones que las previstas en esta Constitución y las que establezcan las leyes, por razones de desarrollo humano, seguridad, sanidad, protección del ambiente u otras de interés social» [...], y el artículo 115 expone que «Se garanti-

${ }^{12}$ CASANOVA GONZÁlEZ, Antonio (2009). ob, an, cit. Páginas 79 a 161. En el mismo orden de ideas, Fermín Lares (2014), "El Expediente del Chavismo (El rojo balance del socialismo del siglo XXI.»1999-2014). Caracas. Edit. Hoja del Norte, clasifica las medidas expropiatorias adelantadas por el Gobierno Nacional en: 1) expropiaciones invocando el interés general; 2) expropiación por la supuesta comisión de ilícitos administrativos o económicos; 2) La toma de inmuebles urbanos; 3) La expropiación de tierras agrarias; 4) La expropiación por la supuesta comisión de delitos penales y 5) La expropiación por supuestos delitos de estafa inmobiliaria. Lo cual al no contar con el apoyo de un conglomerado importante de la población, identificados con los sectores de oposición al gobierno nacional, conllevan a configurar un clima de ingobernabilidad en el país. 
za el derecho de propiedad. Toda persona tiene derecho al uso, goce, disfrute y disposición de sus bienes» [...].

Allan R. Brewer Carías (2001), en sus comentarios sobre la Constitución de 1999, precisa la concordancia del art. 112 constitucional con el artículo 299 del mismo texto y con los artículos 96 y 98 de la Constitución Nacional de 1961. En relación con el artículo 115 de la CRBV, sobre el Derecho de Propiedad, el mismo autor señala su concordancia con los artículos 99 y 101 de la constitución anterior. Lo cual nos permite apreciar la continuidad de la base principista sobre el Derecho de Propiedad en Venezuela.

En el mismo orden de ideas, Fermín Lares (2014) ${ }^{13}$ clasifica las medidas expropiatorias adelantadas por el Gobierno Nacional en: 1) expropiaciones invocando el interés nacional; 2) expropiación porla supuesta comisión de ilícitos administrativos o económicos; 3) La toma de inmuebles urbanos; 4) La expropiación de tierras agrarias; 5) La expropiación por la supuesta comisión de delitos penales y 6)La expropiación por supuestos delitos de estafa inmobiliaria.

\section{REFLEXIONES EN TORNO A LA PROPIEDAD EN LA VENEZUELA ACTUAL}

El Derecho de Propiedad ha evolucionado desde su reconocimiento social como Derecho Natural, anterior a la aparición de los Estados organizados con base en la ley, pasando por las diferentes modalidades de las sociedades políticas hasta llegar a su concepción moderna, la cual reconoce su limitación en función de la utilidad pública o social. Es así como a partir de dicha visión, históricamente los gobiernos han respondido a las necesidades de seguridad nacional, desarrollo de infraestructura pública, el urbanismo, y la construcción de viviendas, entre otros aspectos de su competencia.

No obstante, según cuál sea la orientación ideológico-política del Estado, sus funciones y sus fines, se presentan variaciones en cuanto a la percepción de la función social de la propiedad y la manera como los gobiernos, para el cumplimiento de sus objetivos socio-políticos, deben atenderla.

En Venezuela la regulación de la propiedad es un derecho con rango constitucional, pero también se plasma en la Carta Magna el carácter social de la misma, configurándose así el divorcio con la con-

${ }^{13}$ LARES, FERMíN, ob, ant, cit, págs 168182. 
cepción clásica, o absolutista, bajo cuyo enfoque la propiedad se consideraba inviolable.

$\mathrm{Al}$ respecto Gustavo Linares Benzo (2003), introduce un interesante análisis sobre lo que califica como la bipolaridad constitucional, en donde destaca que ese concepto adquiere rango constitucional en nuestro derecho, por el hecho de garantizarse el derecho a la propiedad en el artículo 115, y a su vez en el mismo artículo permitirse la expropiación por causa de utilidad pública, previo el cumplimiento de ciertas garantías.

Desde los tiempos de La Conquista, pasando por La Colonia, La República, y hasta nuestros días, la distribución de la propiedad de la tierra se ha caracterizado por una ausencia de democratización en su distribución. Lo cual ha mantenido vivo un caldo de cultivo para la protesta histórica y el reclamo de justos derechos por parte de los sectores históricamente excluidos del reparto mayoritario de la riqueza nacional.

En Venezuela se perciben enfrentadas las tesis de la economía centralizada, o bajo el control del Estado, y la denominada economía de mercado. La conceptualización de la Constitución Económica que debió regir a partir de la sanción de la Constitución Nacional de 1999; en el sentido de la delimitación precisa del marco jurídico dentro del cual se debe desarrollar la vida económica de la nación, no fue definida para desarrollar, o atender, el planteamiento político socialista, y la estrategia de desarrollo, planteada posteriormente por la Revolución Bolivariana. Razón por la cual, aunque la base constitucional se percibe clara, se observa una marcada diferencia entre la conceptualización del Derecho de Propiedad entendida y utilizada por los teóricos, planificadores y líderes del sector gobierno, con relación a la base conceptual defendida por los sectores de la oposición.

En ambos casos se acepta la base teórica que define el derecho a la propiedad con rango y tutelaje constitucional, pero en el caso de los afectos al Gobierno Nacional se manifiesta una amplia e imprecisa interpretación del interés y función social, justificándose de esta manera las excepciones a este derecho que se concretan por vía de la ocupación, la expropiación, la confiscación, etc., al considerarse que la propiedad privada, de bienes tipificados como medios de producción o indispensables para el cumplimiento de los fines socio-políticos del Gobierno Nacional (Por ejemplo: seguridad y soberanía alimentaria, construcción de viviendas populares, entre otros) vulnera intereses colectivos, o interfiere en la satisfacción de necesidades de la población. 
De acuerdo con la normativa constitucional venezolana, puede declararse la expropiación de cualquier clase de bienes, en atención a lo previsto en el artículo 115 de la Constitución vigente, que señala que la expropiación puede recaer sobre cualquier clase de bienes susceptibles de apropiación por parte del Estado. En ese sentido, y por mandato constitucional, la Ley de Expropiación por Causa de Utilidad Pública o Social (LECUPS) extiende la potestad expropiatoria a toda cosa corporal o incorporal, mueble o inmueble, tangible o intangible susceptible de ser valorada y sujeta al derecho de propiedad, pero quedando excluidos del ámbito expropiatorio los derechos de las personas y los derechos familiares, así como los bienes del dominio de la República, de los Estados, el Distrito Capital y de los Municipios, que según las respectivas leyes nacionales, estadales o municipales (ordenanzas) no puedan ser enajenados (Artículo 9. ${ }^{\circ}$ de la LECUPS).

De manera tal que, sin lugar a dudas, el ordenamiento constitucional reconoce el derecho a la propiedad, pero al considerar la »utilidad pública y el interés social», como vía de excepción al derecho de propiedad privada, incorpora la posibilidad de realizar expropiaciones. Además, debe mediar una sentencia firme, y la Administración debe cancelar oportunamente el pago de una justa indemnización para proceder con la expropiación. Se aprecia así un trato constitucional de protección para el administrado ante el Estado, cuando los intereses de este se vean enfrentados al interés público, o social.

Sin embargo se concluye que en la práctica no ha sucedido en estricto Derecho así. De lo cual, y sin calificar lo positivo o negativo de la medida, apreciamos que la dinámica política rebasó el accionar administrativo y sus herramientas normativas para atender las afectaciones a la propiedad, y en particular las expropiaciones. Razón por la cual el Ejecutivo Nacional avanzó con la propuesta de reforma del texto constitucional y posteriormente, al ser derrotado en la consulta popular, accionó en procura de sus objetivos mediante la sanción de un conjunto de leyes, que además incluyen en su articulado normativa especial para la materia expropiatoria. En tal sentido, la inserción de una estrategia al respecto en la planificación de carácter nacional se percibe imprecisa, por no decir ausente.

La regulación del Derecho de Propiedad en la República Bolivariana de Venezuela ha evidenciado variaciones fundamentales a partir de la promulgación de la Constitución nacional de 1999, en atención a la orientación político-filosófica que le otorgó el Gobierno Venezolano, y a la priorización en los planes y estrategia de gobierno. Canalizándo- 
se, desde entonces, la acción pública en materia de afectación al Derecho de propiedad por motivaciones varias entre las que destacan la «Política de Seguridad Alimentaria» y los «Programas de Construcción de Viviendas de Interés Social», entre otros.

Es así, como entre los años 2000 al 2015, horizonte de tiempo en el que delimitamos nuestro estudio, se han suscitado en Venezuela una cantidad de afectaciones de activos en propiedad de particulares (ocupaciones, uso y aprovechamiento, expropiaciones, confiscaciones, etc.) sin precedentes en la historia republicana del país, pero con la particularidad de que por un lado el equipo de gobierno, y que lleva estas acciones adelante, ha alegado que las mismas se corresponden con la planificación nacional y la necesidad de socializar el uso, goce y disfrute de los bienes que deben estar al servicio de las mayorías. Por otro lado, los factores políticos de oposición, sectores académicos y gremios de profesionales especializados en la materia, han expuesto que dicha estrategia político-administrativa, y gestión pública, incorpora el desconocimiento a derechos específicos de los propietarios, también tutelados por la máxima norma constitucional; que tiene motivaciones en la orientación socialista de los equipos de gobierno al frente del país desde 1999, y es consecuencia de la improvisación.

Se alega además, que no se ha procedido en estricto apego a los principios universales del Derecho Administrativo, y a la metodología valuatoria de aceptación general, y que, en la mayoría de los casos de expropiación forzosa, no se han cumplido las instancias administrativas y jurisdiccionales, que en estricto apego al Derecho vigente corresponden, para honrar oportuna y satisfactoriamente los requerimientos económicos de los expropiados, a los fines de procurar la aplicación armoniosa, y ajustada a derecho, de la legislación que norma la materia. Lo cual se agrava con la utilización de la llamada «Expropiación de Emergencia», que se activan y desarrollan por vía administrativa por el ente expropiante (mediante el empleo de actos administrativos de rango sub-legal) y antes del cumplimiento de las garantías constitucionales que Amparan el derecho de propiedad, lo cual implica el conocimiento y decisiones por la vía judicial.

Lo cual se ha definido como en un problema de Gobernabilidad Democrática, objeto de evaluación negativa en trabajos varios de investigación académica, e informes de instituciones internacionales con interés en la materia. 